\title{
Friendship and Socialization in the Days of the Covid-19 Pandemic Crisis Research Analysis and Suggestions
}

\author{
Konstantina Diamanti \\ $\mathrm{PhD}$ Candidate \\ Department of Primary Education, University of Ioannina, Greece \\ Tel: +306944606118Ｅ-mail: Konstantina.diamadi@gmail.com
}

Charalampos Barmparousis

Phd, Teaching Staff

Department of Primary Education, University of Ioannina, Greece

Tel: +306932712212Ｅ-mail: Chbarmparousis@gmail.com

Sousanna-Maria Nikolaou (Corresponding author)

Associate Professor

Department of Primary Education, University of Ioannina, Greece

Tel: +302651005875 E-mail: snikola@uoi.gr

Received: December 15, 2021 Accepted: January 3, 2022 Published: January 21, 2022

doi: 10.5296/jsss.v8i2.19488 URL: https://doi.org/10.5296/jsss.v8i2.19488

\begin{abstract}
The Covid-19 pandemic, already completing almost two years of its irreversible course of action, has exerted and still exerts significant pressures on the social and economic systems of countries worldwide as well as on human relations. Human friendship and socialization, as key factors of human coexistence and cooperation within a social group, have been hit hard by the strict imposition of measures of distancing and social isolation in order to limit the
\end{abstract}


disease and stop its unexpectedly deadly transmission. The present study focuses on exploring the effects of the Covid-19 pandemic on friendship and socialization of people in the new different social contexts that have developed. In the first stage, our work attempts a review of the research and studies carried out during these two years which investigate the changes that occurred in these two dimensions of human coexistence and cooperation to highlight the way in which young adults experienced the consequences of lockdown.

Keywords: low case, comma, paper template, abstract, keywords, introduction

\section{Introduction: The Characteristics of the COVID-19 Pandemic}

The Covid-19 pandemic was announced on January 20, 2020 in China and officially declared on March 11, 2020 worldwide (WHO, 2020). In a short period of time, thousands of human lives were lost worldwide and the first and most basic measure that had to be taken immediately was the social isolation of everyone and the confinement in their homes. The socio-economic consequences of the new pandemic affected the primary, secondary and tertiary sectors and this has resulted in rising global unemployment due to job losses (Branquinho et al., 2020).

The Covid-19 pandemic had a huge negative impact on all social relationships. The suddenness of the pandemic and the uncertainty about the length of time it would affect social events caused socio-emotional uncertainty in children, young people and adults. School closures, curfews, quarantines, reduced social activities, fear of putting each person or their family at risk of infection, physical and social exclusion and distancing as key measures to prevent the spread of the disease have caused serious problems in human contacts, especially in the contacts of adolescents and students (Bernasco et al., 2021; Elmer et al., 2020). Although there was plenty of time available to enable each person to engage individually in activities such as painting, reading, and exercise (Branquinho et al., 2020), the lack of interaction created many problems for young people, especially those who were suffering from anxiety, loneliness, depression, irritability, procrastination, discomfort with others, etc. Many have spent invaluable time on the various screens of the home or using substances (Wang et al., 2020; Liang et al., 2020; Pereira et al., 2020). The confinement and forced stay at home caused muscle aches, headaches that were intensified by dietary changes and changes in schedules and normal hours of sleep. At the social level, there was a decrease in social contacts and connections, recreational activities such as various parties or celebrations, while long stays at home and increased interaction with the same people caused an increase in family disputes and breakups and an increase in domestic violence and divorce (Branquinho et al., 2020).

It is noteworthy that in addition to the common conditions that prevailed worldwide as a response by people to the pandemic health crisis, by country, nation, race, age, and identity the effects were different. A study of a multicultural U.S. student population, according to Browning et al. (2021), found that lifestyle changes were mainly associated with lack of motivation, social isolation, and lack of recreational entertainment, lifelong friendship and contact, educational change, uncertainty in professional careers, boredom, frustration and fear as a result of reduced social interaction. 


\section{Friendship and the Effects of the Pandemic. The Research}

According to Aristotle (Nicomachean Ethics, I, 1103a9) the human virtues, the virtues of morality and intellect, the "six", deserve praise and exaltation, "of the six we call the praiseworthy virtues". Virtues guide human actions throughout the course of humanity, they are not "innate" or against human nature, but they can be acquired and cultivated through habits. Friendship is an important and necessary virtue for man, which according to Aristotle leads man to happiness and moral fulfillment, unites citizens and creates bonds between citizens and cities (Nicomachean Ethics, IX 1155a 2). Friendship is "virtue" or it needs virtue as a basis in order to exist and it is necessary for the social inclusion and reference of man. Even the richest man cannot live without friends, because human nature is social, that is, no one can live and function as a unit except through collectivism and socialization (Aristotle, Nicomachean Ethics, IX, 1155a3). Friends are the "refuge" of people of all ages, and according to Aristotle, people who are friends with each other do not need justice, since the most authentic form of justice includes all the features of genuine friendship (Nicomachean Ethics, IX, 1155a).

Friendship according to Fehr (1996: 7) is a "voluntary, personal relationship, usually providing intimacy and help, in which participants like each other and seek each other's company." It is characterized by different forms, depending on the "closeness" of friends, the frequency of contact and the number in the network of friends. It is equivalent to a form of interaction through close intercourse and contact. Different friendship patterns are based on specific personal characteristics and differ depending on gender. For men, friendships are formed depending on how often and for how long they meet each other, while for women friendship is equivalent to a relationship of support and close contact with strong emotions. Socio-economic status and health are two of the most powerful factors in removing someone from their network of friends. The formation of friendship networks proves to be very important because they contribute to the social integration of individuals, offering reassurance, companionship and emotional support in moments of loneliness or depression. Mutual communication and concern are the main characteristics of a friendly relationship (Miche et al., 2013).

In many critical periods of anxiety, melancholy, loneliness and depression, as supported by research, friendship is an essential pillar of mental endurance and resilience and a shield of protection not only for adults but especially for adolescents. In fact, quality friendship emerges stronger than the "sacred" family love and support, which is why a person's time with friends is a real investment and not a pointless act. Close friendships have been shown to be more supportive of stress avoidance and a deterrent to young people's anxiety and internalization (Bernasco et al., 2021). Moreover, "social stress" is associated, according to Biggs et al. (2012), with loose friendships and social isolation. Adolescents who avoid or do not pursue a more meaningful social interaction and friendship seem to end up lacking in social competence and social skills, self-awareness and self-knowledge, which will affect their later adult life as well, as it will not significantly expand their social action beyond their 
close family environment.

According to Aristotle, friendship between people is strong and alive when friends are in communication and physical contact. He also believes that "local distance does not take away friendship, but only friendly energy". In other words, the friendly mood "from within", the intention, the feelings of the friends, do not differ due to distance (Nicomachean Ethics, IX, 1157b5).

With the onset of the Covid-19 pandemic, research has shown, at least in the first phase, that more "loose" friendships become even "looser", while other friendships are not qualitatively affected by online or offline connection and communication (Bernasco et al., 2021). Rice \& Sher (2021) in their research on the consequences of social distancing and distance learning caused by the Covid-19 pandemic, found increased rates of suicide or suicidal moods in adolescents, especially male adolescents. This was interpreted as a result of the fact that male adolescents saw friendship through the prism of physical contact and action, team games and sports. On the contrary, female friendship, because it focuses more on emotional support and verbal expression, has proven to be stronger and more adaptable to the extremes of exclusion and isolation. However, Wang et al. (2020) researching secondary and tertiary students, again in the same context of the effects of the pandemic on friendship networks, found that women used the words "anxiety" and "depression" more often than men and experienced family hardships caused by the pandemic more stressfully.

Despite the fact that distance learning continued through teaching with the use of the internet, virtual social networks proved to be effective in combating youth stress. However, the lack of social company and interactions seems to have a profound effect on students' socio-emotional state, feelings of loneliness and sadness. According to Elmer et al. (2020) friendly and social relations were tested in all phases of the pandemic, either within the family or in an extra-familial environment. At the same time, various interactive networks were created which acted as helpers of social and emotional support in order to reduce the factors that caused stress due to the pandemic. Those who had strong friendships "survived" emotionally and did not lose their motivation for life and social interaction, while those who had "loose" friendships, were isolated and felt more stress and introversion.

Research by Branquito et al. (2020) on the effects of the Covid-19 pandemic on friendships found that high school students changed their mood significantly and were overly nostalgic for moments with their classmates. The need to communicate regularly with their peers had negative consequences on their psychosomatic health. The fear of transmitting the virus to the family prevented them from any natural social interaction. In the age group of students it was found that most experienced anxiety, loneliness and depression while they had different attitudes and behaviors in their way of studying. They significantly changed their behavior on social networks with limited social interactions and less connectivity to networks of entertainment and collaborative learning. Of course, those social contacts strongest before the pandemic were maintained during social distancing with digital communication keeping the relationships active. However, it was found that those most isolated from social interaction and collaborative learning, who had previously had this attitude and behavior, were not 
integrated into the networks and at greater risk of suffering the negative effects of the pandemic (Elmer et al., 2020).

\section{The Socialization and Effects of the Pandemic. The Research}

A general definition of the term "socialization" includes the way in which an individual experiences a process of learning and accepting the rules and principles of a group or part of a social whole in order to integrate into it (Ritzer, 2018: 156-157). Emile Durkheim, the mouthpiece of sociological thought, identified, in the early 20th century, socializing as the process of the transition of man from the world of biology to the world of the social "scene" with all the processes of growth and formation of his personality with his fellow human beings and the wider environment that surrounds him. The collective with the individual element are in a constant "interaction" and with "conscious and unconscious" processes the formation of the "socio-cultural personality" of the individual takes place. Continuing this thinking and the functionalism approach in general, Parsons identifies socialization as "the internalization of the culture of the particular society in which the individual was born [...] and the gradual integration of the child into ever wider subsystems." Through this process of integration, the individual acquires his personality system and internalizes the semantic contents of the respective political system" (Nikolaou, 2009: 72-73). For Parsons, socialization is one of the basic functions of education along with "choice", which leads to balance and social organization but also a long process of five phases of "internalization of culture" of a certain social status quo (Nikolaou, 2009: 21; 72-73).

The main feature of socialization is the "interaction", the way the receiver, the new social member, responds to the message of the transmitter; that is, the one who tries to transfer the experiences to the new social member so that he integrates smoothly into society (Ritzer, 2018: 156-157). New ideals and new values determine the behavior of the individual in his social environment (Nikolaou, 2009: 72). According to Ritzer, there are eight stages of socialization of man, from the moment of his birth until his death. In a general context, the bodies, socialization are divided into primary, concerning family and friends, and secondary, involving impersonal influences such as education and the media (Ritzer, 2018: 156-157).

Socialization as a process regulates the socio-cultural values and structures of the social system and its absence hinders the evolutionary social course of man, forcing him to remain at a subhuman level. The exclusion of people from social company and interactions implies the existence of "unchanged damage" on a mental and emotional level (Nikolaou, 2009: 22).

In the context of the socialization process, the individual communicates, socializes with friends, people of approximately the same age, feels happy and develops relationships and attitudes within the group context that he has chosen to join (Nikolaou, 2009: 74). People of the same age are an important body of the socialization of the individual and for pupils or students socialization takes place inside and outside the learning environment. In fact, quite often there is a friction or a confrontation between the primary actors of socialization, that is, the different views of friends come into ideological or moral conflict with the perceptions of the family or even with other secondary actors. The socialization that takes place in the company of people of the same age is especially important in all age phases of the person, 
because peers-friends are the supports of the individual in work, study or social integration in smaller groups (Ritzer, 2018: 159).

It is worth noting that socialization as a process of integration of the individual in society, has different elements and specifications regarding gender. Traditional patterns, structures and social institutions differentiate boys from girls, with distinct roles and corresponding behaviors (Ritzer, 2018: 159-160). In the workplace, adult socialization or even "re-socialization" takes place, in cases such as when people are looking for work and are often forced to modify their ideas, rules or values to integrate into the new reality (Ritzer, 2018: 164).

Everything that happens in society also affects the process of socialization. For example, the Covid-19 pandemic, with its restrictions on social contacts and the imposition of compulsory social distancing, brought about sudden changes in people's daily lives. A new way of communicating and thus socializing, the "internet socialization" with internal activities, was formed and expanded, which often caused new habits, and dependencies on electronic devices or substance use to some who were vulnerable even before the pandemic (Kar et al., 2020). But the long-lasting social isolation also caused anxiety and loneliness, intensifying the need for socializing. According to Marmarosh et al. (2020) many groups, online psychotherapies have proven to be life-saving in treating large numbers of people suffering from the traumatic impact of the pandemic. Group therapy was a form of socialization and served as an antidote to the imposition of social distancing from any kind of social action.

In this new pattern of socialization, according to Kotera et al. (2020), some university professors systematically and consciously implemented morning online meetings online gatherings. In fact, they put into practice daily morning communication and interaction on a digital platform (e.g., Microsoft Teams / MS Teams) in order to create a new communication network, to enhance a positive team spirit and culture and to prevent loneliness and isolation through team consolidation. Isolation and marginalization as a feeling in the educational practice is very difficult to manage and can negatively affect the result and the work of the teacher. This new form of socialization has highlighted the importance of cohesion and mutual support at the human level in times of crisis and danger such as the pandemic.

According to Elmer et al. (2020) a relationship of interaction and interdependence of their social networks has developed in the pupil and student community during this period of the pandemic, but also a change in their ways of connecting due to the exclusion of universities and strict social distancing measures. Some people seem to find it difficult to "socialize" in the new reality of digital communication, despite the fact that their communication and support is necessary due to the negative consequences of isolation. Reducing contact with family or some friends equates to limited social support and a lower degree of integration into student social networks. In fact, the study found that female students were more concerned about their family and friends, more anxious about their future careers, spent less time on social media and were much less socially supported, making them more vulnerable mentally than male students (Elmer et al., 2020). 
Due to the social constraints, the socialization of people was greatly limited to digital media which on the one hand functioned as information tools and on the other hand seem to have compensated for the social deficit and partially met the emotional needs of people, although physical, lifelong contact and interaction is considered irreplaceable (Merchant \& Lurie, 2020; Jarzyna, 2020). According to O'Keefe \& Clarke-Pearson (2011), social media is one of the most popular new media habits for socializing, entertaining and communicating, although these sites are often not the healthiest environments. During the pandemic, however, they emerged as very important for maintaining social contact and the continuation of socialization through the new online form. Live contact and communication may have been reduced or even interrupted, but it was maintained through the digital-virtual world and social networks (Facebook, Twitter, Instagram) which contributed substantially to the maintenance of human relationships. The interactive and social element of this relationship, that is, people with social media, was a real support in the new and different everyday life. In fact, it is currently argued that the benefits do not relate to socialization, even digital, but offer a comprehensive set of knowledge and methods for dealing with future crises and disasters (Pitas \& Ehmer, 2020).

Social networking platforms such as Facebook, Twitter, Instagram, Tik-Tok, various online group video games and frequent Netflix viewing have been offered and have become the imperative, social and communication support for people of all ages, from infants to the elderly from the beginning of the pandemic onwards, on the grounds that loneliness and social isolation will be reduced. In this way, new technologies in the context of the fourth industrial revolution formed a new form of socialization, "virtual socialization", as platforms and social media employed more than 2.9 billion people (Jarzyna, 2020).

In general and according to the research findings so far and without comparable data we can not know the exact effects of the closure of schools due to the pandemic in terms of social skills and knowledge of students and young people. It is likely, however, that losses in students' learning time and skills will have long-term consequences. According to the research of Hanushek \& Woessmann, (2020: 9) a group of students who lose the ability to develop skills that a child usually acquires in one third of the school year has the consequence of reducing the future GDP of a country by $1,5 \%$ on average for the rest of a century $(2.2 \%$ if half a school year is lost) (Konle-Seidl \& Picarella, 2021).

\section{Conclusions}

A key conclusion reached by the research in general is that with the COVID-19 pandemic we experienced multidimensional and unprecedented challenges for young people and education systems. This period reveals how unprepared global society is to manage crises and how unprepared and structurally weak education is to make proper use of new technologies through digital education. Research on behalf of Europe has shown, for example, that the education and youth sectors face particular challenges, and that a common ground for European countries should be to build more resilient education systems that respond to and adapt to future crises (Van der Graaf et al., 2021).

Especially for young people, it must be emphasized how significantly they were affected by the closure of schools or restrictions on training opportunities, and low levels of mental 
well-being with reference to social distancing, loneliness, depression and general social isolation were also found as a negative result of the pandemic. It has also been pointed out that the loss of learning leads to increased repetition of courses, without necessarily compensating for the lack of skills that should have been developed at that time, and therefore a lower educational level even in higher education and as a result reduced income and increased unemployment (Jaume \& Willém, 2019). In relation to the pandemic and according to data from the European Union, the indicators so far do not provide a clear picture of whether there will be a long-term deterioration of the employment and social status of young people (Konle-Seidl \& Picarella, 2021).

More specifically, social support, coexistence with others in various forms of interaction, cooperation, friendship, social relations and learning or study in a group context, physical or even digital, as found in research findings, (Elmer et Browning et al., 2021) have a positive effect on school and university progress, personality development and personal fulfillment. In the new reality we are experiencing with the Covid-19 pandemic it is considered very important:

A) to support pupils and students not only in learning but also in school and university socialization. This means supporting the development of social and friendly networks, building social contacts and connections with other pupils / students,

B) to contribute as much as possible to the maintenance of friendship and close contact, in spite of any social constraints, in order to avoid the negative consequences of isolation,

C) to encourage regular communication with family and friends, engaging in enjoyable activities and developing a "common sense" that supports "common resilience" (Vinkers et al., 2020),

D) to develop for the duration of the pandemic internet groups on digital platforms through which learning and study will be carried out collaboratively, the implementation of sessions by peer groups and the appropriate counseling and guidance in order to deal with the negative effects of social restriction (Elmer et al., 2020),

E) for schools and universities to take care of the preparation and training of pupils / students in the new form of socialization, the digital, so that they are ready to respond to forms of interaction and other social conditions and contexts. It would be advisable for online events using a digital platform to create digital groups for the development of social ties especially for young pupils and students who did not have time to develop social relationships in the learning space,

F) if the model of open structures in education is maintained after almost two years of isolation and distance education, to apply the hybrid education model (blended or hybrid learning) that combines the traditional teaching space and educational distance learning activities with the support of technology, especially for new students in higher education (Caner, 2012), to gradually escape from the social conditions and contexts of incarceration and to build social relationships and connections with other students in online and live events and gradually return to a natural form of socialization as a necessary condition for the 
evolutionary course of the social subject,

G) as research has finally shown how important it is, to try to maintain friendship and close contact, even in the form of online socialization, despite any social restrictions that need to be imposed each time to avoid very important negative consequences for humans.

In order to avoid a "lost" generation or a generation with a variety of irreversible problems, it is important to pay special attention to young people during the recovery phase. The challenge will be to implement dynamic policies by taking appropriate action. To address the social and emotional health of young people, policy makers should also be competent and work in a coordinated and intensive manner by integrating policies into educational settings, workplaces and welfare systems to achieve recovery and resilience. According to EU data from the 22 countries that participated in the OECD survey in February 2021, only 12 countries have taken initiatives in this direction. It is therefore vital to provide policy guidance and support for targeted actions and structural reforms for the social and psycho-emotional development and health of young people (Konle-Seidl \& Picarella, 2021).

\section{References}

Aristotle. Nicomachean Ethics. Introduction, translation, comments by Lypourlis, D., Zitros: Athens 2006.

Bernasco, E. L., Nelemans, S. A., van der Graaff, J., \& Branje, S. (2021). Friend Support and Internalizing Symptoms in Early Adolescence During COVID-19. Journal of Research on Adolescence, 31(3), 692-702. https://doi.org/10.1111/jora.12662

Biggs, B. K., Vernberg, E. M., \& Wu, Y. P. (2012). Social Anxiety and Adolescents' Friendships: The Role of Social Withdrawal. The Journal of Early Adolescence, 32(6), 802-823. https://doi.org/10.1177/0272431611426145

Blackledge, D., \& Hunt, B. (2000). Sociology of education (translated by M. Deligianni). Athens: Metaichmio.

Branquinho, C., Kelly, C., Arevalo, L. C., Santos, A., \& Gaspar de Matos, M. (2020). "Hey, we also have something to say": a qualitative study of Portuguese adolescents' and young people's experiences under COVID-19. Journal of Community Psychology; 48(8), 2740-2752. https://doi.org/10.1002/jcop.22453

Browning, M. H., Larson, L. R., Sharaievska, I., Rigolon, A., McAnirlin, O., Mullenbach, L., \& Alvarez, H. O. (2021). Psychological impacts from COVID-19 among university students: Risk factors across seven states in the United States. PloS one, 16(1), e0245327. https://doi.org/10.1371/journal.pone.0245327

Caner, M. (2012). The Definition of Blended Learning in Higher Education. In P. Anastasiades (Eds.), Blended Learning Environments for Adults: Evaluations and Frameworks (pp. 19-34). IGI Global.

Canete, J. (2021). The social paradox of COVID-19 pandemic: the duality of socialization and the value of fraternal charity. Journal of public health (Oxford, England), 43(2), e413-e414. https://doi.org/10.1093/pubmed/fdab114 
Elmer, T., Mepham, K., \& Stadtfeld, C. (2020). Students under lockdown: Comparisons of students' social networks and mental health before and during the COVID-19 crisis in Switzerland. Plos one, 15(7), e0236337. https://doi.org/10.1371/journal.pone.0236337

Fehr, B. (1996). Friendship processes. Thousand Oaks, CA: Sage Publications.

Hanushek, E. A., \& Woessmann, L. (2020). The Economic Impacts of Learning Losses. OECD 2020. Retrieved from

https://www.oecd.org/education/The-economic-impacts-of-coronavirus-covid-19-learning-los ses.pdf

Jaume, D., \& Willém, A. (2019). The long-run effects of teacher strikes. Evidence from Argentina. Journal of Labor Economics, 37(4), 1097-1139.

Kar, S. K., Arafat, S., Sharma, P., Dixit, A., Marthoenis, M., \& Kabir, R. (2020). COVID-19 pandemic and addiction: Current problems and future concerns. Asian journal of psychiatry, 51, 102064. https://doi.org/10.1016/j.ajp.2020.102064

Konle-Seidl, R., \& Picarella, F. (2021). Youth in Europe: Effects of COVID-19 on their economic and social situation, Publication for the committee on Employment and Social Affairs, Policy Department for Economic, Scientific and Quality of Life Policies, European Parliament, Luxembourg.

Kotera, Y., Green, P., Rhodes, C., Williams, A., Chircop, J., Spink, R., Rawson, R., \& Okere, U. (2020). Dealing With Isolation Using Online Morning Huddles for University Lecturers During Physical Distancing by COVID-19: Field Notes. International Review of Research in Open and Distributed Learning, 21(4), 238-244. https://doi.org/10.19173/irrodl.v21i4.4843

Liang, L., Ren, H., Cao, R., Hu, Y., Qin, Z., Li, C., \& Mei, S. (2020). The Effect of COVID-19 on Youth Mental Health. The Psychiatric quarterly, 91(3), 841-852. https://doi.org/10.1007/s11126-020-09744-3

Marmarosh, C. L., Forsyth, D. R., Strauss, B., \& Burlingame, G. M. (2020). The psychology of the COVID-19 pandemic: A group-level perspective. Group Dynamics: Theory, Research, and Practice, 24(3), 122-138. https://doi.org/10.1037/gdn0000142

Merchant, R. M., \& Lurie, N. (2020). Social media and emergency preparedness in response to novel coronavirus. Jama, 323(20), 2011-2012. https://doi:10.1001/jama.2020.4469

Miche, M., Huxhold, O., \& Stevens, N. L. (2013). A latent class analysis of friendship network types and their predictors in the second half of life. The journals of gerontology. Series B, Psychological sciences and social sciences, 68(4), 644-652. https://doi.org/10.1093/geronb/gbt041

Nikolaou, S. M. (2009). Theoretical Issues in the Sociology of Education (2nd ed.). Athens: Gutenberg.

Nikolaou, S. M. (2009). Socialization at school. Athens: Gutenberg.

O'Keeffe, G. S., \& Clarke-Pearson, K. (2011). The impact of social media on children, adolescents, and families. Pediatrics, 127(4), 800-804. 
https://doi.org/10.1542/peds.2011-0054.

Pereira, M. D., Oliveira, L. C. de, Costa, C. F. T., Bezerra, C. M. de O., Pereira, M. D., Santos, C. K. A. dos, \& Dantas, E. H. M. (2020). The COVID-19 pandemic, social isolation, consequences on mental health and coping strategies: an integrative review. Research, Society and Development, 9(7), e652974548. https://doi.org/10.33448/rsd-v9i7.4548

Pitas, N., \& Ehmer, C. (2020). Social Capital in the Response to COVID-19. American Journal of Health Promotion, 34(8), 942-944. https://doi.org/10.1177/0890117120924531

Rice, T., \& Sher, L. (2021). The men's mental health perspective on adolescent suicide in the COVID-19 era. Acta neuropsychiatrica, 33(4), 178-181. https://doi.org/10.1017/neu.2021.10

Ritzer, G., (2018), Introduction to Sociology, Collective Volume 4 the version. (translated by Polymatidou, P.) Tziola: Athens.

Vinkers, C. H., van Amelsvoort, T., Bisson, J. I., Branchi, I., Cryan, J. F., Domschke, K., Howes, O. D., ... van der Wee, N. (2020). Stress resilience during the coronavirus pandemic. European neuropsychopharmacology: the journal of the European College of Neuropsychopharmacology, 35, 12-16. https://doi.org/10.1016/j.euroneuro.2020.05.003

Van Zalk, N., Van Zalk, M., Kerr, M., \& Stattin, H. (2011). Social anxiety as a basis for friendship selection and socialization in adolescents' social networks. Journal of personality, 79(3), 499-525. https://doi.org/10.1111/j.1467-6494.2011.00682.x

Wang, C., Pan, R., Wan, X., Tan, Y., Xu, L., Ho, C. S., \& Ho, R. C. (2020). Immediate Psychological Responses and Associated Factors during the Initial Stage of the 2019 Coronavirus Disease (COVID-19) Epidemic among the General Population in China. International journal of environmental research and public health, 17(5), 1729. https://doi.org/10.3390/ijerph17051729

World Health Organization. (2020). Coronavirus disease 2019 (COVID-19): situation report, 73. World Health Organization. Retrieved from https://apps.who.int/iris/handle/10665/331686

Van der Graaf, L., Dunajeva, J., Siarova, H., \& Bankauskaite, R. (2021). Research for CULT Committee - Education and Youth in Post-COVID-19 Europe - Crisis Effects and Policy Recommendations, European Parliament, Policy Department for Structural and Cohesion Policies, Brussels.

Jarzyna C. L. (2020). Parasocial Interaction, the COVID-19 Quarantine, and Digital Age Media. Human Arenas, 1-17. Advance online publication.

https://doi.org/10.1007/s42087-020-00156-0

\section{Copyright Disclaimer}

Copyright for this article is retained by the author(s), with first publication rights granted to the journal.

This is an open-access article distributed under the terms and conditions of the Creative Commons Attribution license (http://creativecommons.org/licenses/by/3.0/). 